\title{
COMPARATIVE STUDY OF INTRAPROSTATIC INFILTRATION WITH LIDOCAINE INJECTION AND PERIPROSTATIC NERVE BLOCK FOR PAIN FREE TRUS GUIDED PROSTATE BIOPSY
}

\author{
AMIRUL ISLAM ${ }^{1}$, MD. NAZRUL ISLAM ${ }^{2}$, MD. JAHANGIR ALAM ${ }^{1}$, MARUF AHMED²
}

${ }^{1}$ Department of Urology, Sheikh Sayera Khatun Medical College.Gopalgong, ${ }^{2}$ Department of Urology, Sher-E-Bangla Medical College, Barisal, ${ }^{3}$ Department of Urology, Sheikh SayeraKhatun Medical College.Gopalgong, ${ }^{2}$ Department of Urology, Sher-E-Bangla Medical College, Barisal.

\begin{abstract}
:
Objectives: To compare the efficacy of intraprostatic infiltration of lidocain injection and periprostatic nerve block for pain free TRUS guided prostate biopsies.

Methods: A hospital based prospective experimental study was conducted in the Department of Urology of Dhaka Medical College Hospital, Dhaka from July 2007 to June 2009 to compare the different anesthesia technique for TRUS guided prostate biopsy for the detection of carcinoma prostate. All male patients aged over 55 years having lower urinary tract symptoms (LUTS) attending to urology OPD as well as in patient department were evaluated by history, physical examination including $D / R / E$ and necessary investigations to identify the potential candidates for prostate biopsy and potential participants were counselled for prostate biopsy. Before taking biopsy patients were again judged by selection and exclusion criteria. Overall general examination as well as examination of urinary system and anorectal region was done. DRE was done to see the size, consistency and nodularity of prostate prior to biopsy.

Who fulfilled the selection criteria included in this study in out patient basis or admitted in the urology ward and numbered chronologically, odd numbers for group-I includes periprostatic nerve block and even numbers for group-Il includes intraprostatic infiltration of lidocain injection.

They underwent 10 core prostate biopsy (standard 6 plus lateral 4 core) and hypoechoic lesion directed biopsy to see the unique cancer detection rate in each lobe. Data were analyzed using SPSS (Statistical package for social science) software program. The test of significance were chi-square, student $t$ test, Fisher exact test, Mann Whitney test. Probability value ( $P$ Value $<0.05)$ was considered significant.

Results: Intensity of pain using visual analogue scale (VAS) demonstrates that the mean pain intensity during probe insertion was significantly less in Group-I than that in Group-II (5.8 1.3 vs. $6.7 \pm 1.3, p=0.007$ ). The mean pain intensity during anesthesia was also significantly less in the former group compared to the latter group $(4.5 \pm 1.2 \mathrm{vs} .5 .1 \pm 1.1, p=0.036)$. Then the pain intensity of both the groups decreased, but the decrease was significantly faster and steeper in Group-II than in Group-I ( $p=0.001)$. The pain intensity of Group-II 30 minutes after biopsy further decreased to $1.9 \mathrm{~cm}$ on visual analogue scale, while the pain intensity of Group-l increased from $4.1 \mathrm{~cm}$ during biopsy to $4.4 \mathrm{~cm} 30$ minutes after biopsy $(p<0.001)$.

Results of the study revealed that -intraprostatic administration of local anesthesia significantly decreases the pain associated with prostate biopsy compared with conventional periprostatic nerve block.

Conclusions: Intraprostatic administration of local anesthesia significantly decreases the pain associated with prostate biopsy compared with periprostatic nerve block. It is a simple, safe and rapid technique that should be considered in all patients undergoing transrectal ultrasound guided prostate biopsy.
\end{abstract}

Bangladesh J. Urol. 2017; 20(2): 87-93

Correspondence: Dr. Amirul Islam, Dept. of Urology, Sheikh Sayera Khatun Medical College, Gopalgong. E mail-dramirulislamuro@gmail.com 


\section{Introduction :}

Prostate cancer is one of the major health problems in all over the world. Prostate cancer is detected by prostate biopsy, which is a painful procedure. $6090 \%$ of patients report discomfort or pain when undergoing a prostate biopsy, which may be mild or severe and even cause vasovagal episode. Pain causes a clear reduction in the number of biopsies obtained during the procedure and therefore the rate of detection of prostate carcinoma[3].

Transrectal Ultrasound (TRUS) guided prostate biopsy is the most commonly used procedure for detection of prostate cancer. It is considered safe and commonly performed on an out patient basis. Approximately $5,00,000$ prostatic biopsies are performed in USA annually[1].

Recent studies demonstrated the advantage of an increased number of biopsy cores compared with the standard sextant core biopsy protocol ${ }^{7}$. Periprostatic nerve block (PNB) is the most common anesthesia technique used before prostate biopsy, pain control by PNB is not completely satisfactory and several prospective, randomized trials of other methods, such as anesthetic gel or sedation, that tried to improve pain control in combination with PNB[12], direct intracapsular anesthesia can give better pain control than conventional periprostatic anesthesia[8].

In addition, as the number of biopsy specimens increases, discomfort tends to become more severe. A randomized, double-blind study demonstrated that periprostatic administration of local anesthesia was not effective in 12 core biopsy, indicating that the usefulness of this method remains unclear[7]. Therefore, a simple and more valid method of pain relief is necessary. There is a new method of local anesthesia, namely intraprostatic anesthesia and compared it with conventional periprostatic anesthesia in terms of pain relief and morbidity.

\section{Materials and Methods}

This Hospital based Quasi experimental study done in Department of Urology, Dhaka Medical College and Hospital. at the Period of July 2007 to June 2009. In this prospective study sixty consecutive patients were selected as per selection criteria from the patients attending in the out patient department as well as in patient department of urology unit, Dhaka Medical College Hospital, Dhaka with the complaints of LUTS. The patients with above mentioned complaints were evaluated by detail history, physical examinations including $D / R / E$ and by urinalysis, urine culture and sensitivity, complete blood count (CBC), ultrasonography of KUB region and S.PSA. Then suspected cases of carcinoma prostate who fulfilled the selection criteria included in this study in out patient basis or admitted in the urology ward and numbered chronologically and devided into two groups on the basis of odd and even number. Odd numbers for group-I, includs periprostatic nerve block and even numbers for group-II, includs intraprostatic infiltration of lidocain injection. Inclusion criteria were, abnormal DRE findings of prostate with or without elevated PSA (level $>4.0 \mathrm{ng} / \mathrm{ml}$ ), abnormal PSA level even in normal DRE findings.

\section{Exclusion criteria were:}

Patient having any painful anal and rectal conditions, Patient having bleeding diathesis, patient having previously undergone prostatic biopsy, active Infections (UTI or prostatitis etc). Drug history with special attention to antithrombotic and anticoagulant medication like aspirin, clopidogrel, warferin was taken.

Then TRUS was done by biplanar $7.5 \mathrm{MHz}$ endocavitary ultrasound probe covered by condom. Prostate was measured in 3 dimensions and the volume was estimated. All hypoechoic lesions were noted . A 22gauge, $15-\mathrm{cm}$ spinal needle with was used to inject 10 $\mathrm{mL}$ of $2 \%$ idocaine anesthetic agent without epinephrine using the following techniques.

Operating Instruments were Monopty gun, Ultrasound machine, Trans rectal probe and Needle guide (Adapter). Disposable syringe, 2\% Lidocaine Injection.

Two minute after injection with lidocain, Compatible needle guide and additional condom were applied to cover TRUS probe and needle guide. Biopsies were taken by using monopty gun with $18 \mathrm{G}$ needle. 10 core biopsies were obtained in the midlobar para sagital plane, halfway between the lateral edge and midline of the prostate gland, at the base, mid gland and apex.

Four lateral biopsies were taken from just medial to the lateral border of prostate at base and mid gland level bilaterally. However biopsies of all hypoechoic lesions were performed. Tissue was preserved in $10 \%$ formalin each lobe in a separate container and sent for histopathology. Within two minutes of the procedure completion, the patients were asked to grade their pain experienced during four situation including when the TRUS probe was inserted, during anesthesia, during biopsy and 30 minutes after biopsy. The pain score was assessed using a visual analog linear 10 point scale (range 0 to 10, 0-no pain, 10-excruciating pain).

Data were analyzed using SPSS (Statistical Package for Social Science, version 12). The test statistics used to analyze the data were descriptive statistics and McNamara's chi-square test, t-test, Fisher exact test and Mann whitny test. The level of significance was set at 0.05 and $\mathrm{P}<\mathrm{O} .05$ was considered significant. 


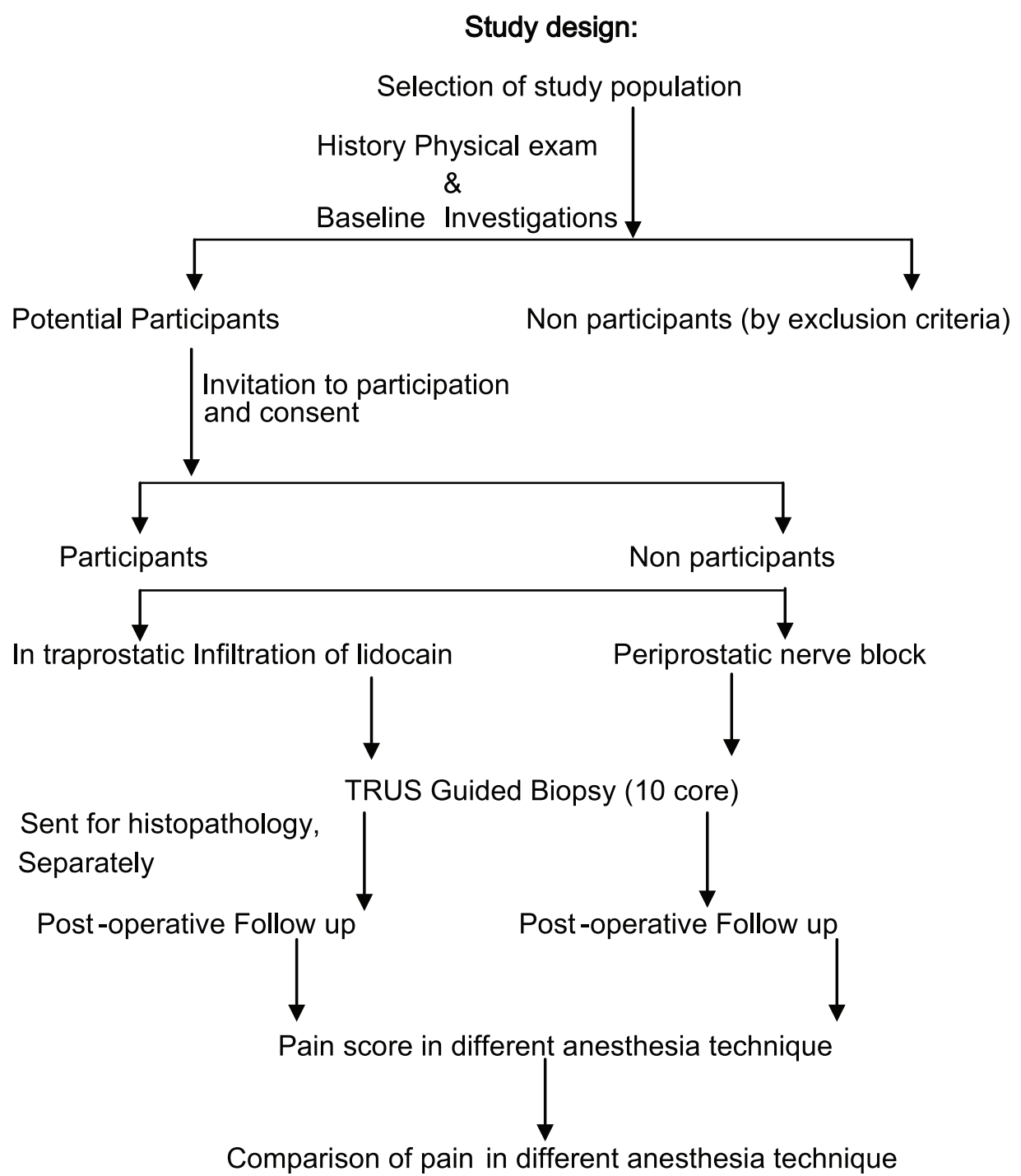

Results:

In this study we included 60 patients of clinically suspected cases of prostatic carcinoma in two groups, one group received periprostatic nerve block with lidocaine (Group-I,odds number) and another group received intraprostatic lidocaine infiltration (Group-II,even number). The findings obtained from data analysis were, the mean age was almost identically distributed between the two groups $(68.1 \pm 4.7$ vs. $67.7 \pm 4.6, p=0.734)$.

Table II shows the baseline characteristics of the study subjects. Majority (71.4\%) of the patients of Group-I and $53.1 \%$ of Group-II were found positive on digital rectal examination (DRE) $(p=0.146)$. The mean serum PSA of Group-I and Group-II were almost equal ( $p=0.618)$. Presence of RBC in urine was found in $14.3 \%$ and $18.8 \%$ of Group-I and Group-II respectively. Majority of the patients of Group-I (96.4\%) and Group-II (90.6\%) had volume of prostate $<50 \mathrm{cc}(\mathrm{p}=0.359)$.
Table I Age distribution between groups

\begin{tabular}{lccc}
\hline Baseline variables & \multicolumn{2}{c}{ Group } & $\begin{array}{c}\text { p- } \\
\text { value }\end{array}$ \\
\cline { 2 - 3 } & $\begin{array}{c}\text { Group-I } \\
(n=28)\end{array}$ & $\begin{array}{c}\text { Group-II } \\
(n=32)\end{array}$ & \\
\hline Age (years) & & & \\
$<65$ & $7(25.0)$ & $9(28.1)$ & 0.734 \\
$\geq 65$ & $21(75.0)$ & $23(71.9)$ & \\
Mean \pm SD & $68.1 \pm 4.7$ & $67.7 \pm 4.6$ & \\
\hline
\end{tabular}

\# Student's t-Test was done to analyse the data.

Figures in the parentheses denote corresponding \%

More than one-third (35.7\%) of patients of Group-I had no lesions, $28.6 \%$ single lesion, another $28.5 \% 2$ lesions and $7.1 \% 3$ lesions as detected by TRUS. In Group-II, $53.1 \%$ did not have any lesions, $28.1 \%$ single lesion, 
$18.8 \% 2$ lesions and none had 3 lesions. The groups were similar in terms of number of lesion $(p=0.271)$ (Table III).

Table II Distribution of patients by baseline variables between groups

\begin{tabular}{|c|c|c|c|}
\hline \multirow[t]{2}{*}{ Baseline variables } & \multicolumn{2}{|c|}{ Group } & \multirow{2}{*}{$\begin{array}{c}p- \\
\text { value }\end{array}$} \\
\hline & $\begin{array}{l}\text { Group-I } \\
(n=28)\end{array}$ & $\begin{array}{l}\text { Group-II } \\
(n=32)\end{array}$ & \\
\hline \multicolumn{4}{|l|}{$\overline{\text { DRE }^{\#}}$} \\
\hline Positive & $20(71.4)$ & $17(53.1)$ & 0.146 \\
\hline Negative & $8(28.6)$ & $15(46.9)$ & \\
\hline Serum PSA $(n g / m l)^{\top}$ & \multicolumn{3}{|c|}{$40.3 \pm 21.037 .4 \pm 22.90 .618$} \\
\hline \multicolumn{4}{|l|}{ RBC in urine $\#$} \\
\hline Present & $4(14.3)$ & $6(18.8)$ & 0.908 \\
\hline Absent & $24(85.7)$ & $26(81.3)$ & \\
\hline \multicolumn{4}{|l|}{ Volume of prostate* } \\
\hline$<50 \mathrm{cc}$ & $27(96.4)$ & $29(90.6)$ & 0.359 \\
\hline $\mathrm{e}^{\mathrm{TM}} 50 \mathrm{cc}$ & $1(3.6)$ & $3(9.4)$ & \\
\hline
\end{tabular}

\#Chi-square $\left(\chi^{2}\right)$ Test was done to analyse the data; * Fisher's Exact Test was employed

If Mann-Whitney Test was done to analyse the data.

Figures in the parentheses denote $\%$

Table III Comparison of number of prostate lesions between groups

\begin{tabular}{lccc}
\hline No. of lesions & \multicolumn{2}{c}{ Group } & $p$ - \\
& $\begin{array}{c}\text { Group-I } \\
(\mathrm{n}=28)\end{array}$ & $\begin{array}{c}\text { Group-II } \\
(\mathrm{n}=32)\end{array}$ & value \\
\hline No lesion & $10(35.7)$ & $17(53.1)$ & \\
1 lesion & $8(28.6)$ & $9(28.1)$ & 0.271 \\
2 lesions & $8(28.6)$ & $6(18.8)$ & \\
3 lesions & $2(7.1)$ & $0(0.0)$ & \\
\hline
\end{tabular}

Chi-square $\left(\chi^{2}\right)$ Test was done to analyse the data;

Figures in the parentheses indicate corresponding percentage.

Intensity of pain using visual analogue scale (VAS) demonstrates that the mean pain intensity during probe insertion was significantly less in Group-I than that in Group-II (5.8 \pm 1.3 vs. $6.7 \pm 1.3, p=0.007)$. The mean pain intensity during anesthesia was also significantly less in the former group compared to the latter group $(4.5 \pm 1.2$ vs. $5.1 \pm 1.1, p=0.036)$. Then the pain intensity of both the groups decreased, but the decrease was significantly faster and steeper in Group-II than that in Group-I ( $p=0.001)$. The pain intensity of Group-II 30 minutes after biopsy further decreased to $1.9 \mathrm{~cm}$ on visual analogue scale, while the pain intensity of GroupI increased from $4.1 \mathrm{~cm}$ during biopsy to $4.4 \mathrm{~cm} 30$ minutes after biopsy $(p<0.001)$ (Table IV).

Table IV Intensity of pain using visual analogue scale between groups

\begin{tabular}{lccc}
\hline $\begin{array}{l}\text { Intensity of pain using visual } \\
\text { analogue scale (VAS 0-10 cm) }\end{array}$ & $\begin{array}{c}\text { Group-I } \\
(\mathrm{n}=28)\end{array}$ & $\begin{array}{l}\text { Group-II } \\
(\mathrm{n}=32)\end{array}$ \\
\hline VAS during probe insertion & $5.8 \pm 1.3$ & $6.7 \pm 1.3$ & 0.007 \\
VAS during anesthesia & $4.5 \pm 1.2$ & $5.1 \pm 1.1$ & 0.036 \\
VAS during biopsy & $4.1 \pm 1.3$ & $3.0 \pm 1.0$ & 0.001 \\
VAS 30 minutes after biopsy & $4.4 \pm 1.4$ & $1.9 \pm 1.1<0.001$ \\
\hline Data were analysed using Student's & t-Test and were \\
presented as mean \pm SD. & &
\end{tabular}

Table V Distribution of patients by pain location between groups

\begin{tabular}{lcc}
\hline Pain location & \multicolumn{2}{c}{ Group } \\
& $\begin{array}{c}\text { Group-I } \\
\left(\mathrm{n}=28^{*}\right)\end{array}$ & $\begin{array}{c}\text { Group-II } \\
\left(\mathrm{n}=32^{*}\right)\end{array}$ \\
\hline Rectum/Anus & $22(78.6)$ & $30(93.7)$ \\
Penis & $12(42.9)$ & $7(21.8)$ \\
Scrotum/Testis & $5(17.8)$ & $1(3.1)$ \\
Abdomen & $3(10.7)$ & $0(0.0)$ \\
\hline
\end{tabular}

${ }^{*}$ Total will not correspond to $100 \%$ for multiple pain site in individual patients.

Histopathological diagnosis of biopsy material demonstrates that $57.1 \%$ of Group-l and $43.7 \%$ of Group-II had carcinoma prostate and the rest of the respective groups had benign hyperplasia of prostate (BPH) (Table VI).

Table VI Findings of histopathological diagnosis of biopsy material

\begin{tabular}{lccc}
\hline $\begin{array}{l}\text { H/P diagnosis of biopsy } \\
\text { material }\end{array}$ & \multicolumn{2}{c}{ Group } & $p-$ \\
& $\begin{array}{c}\text { Group-I } \\
(\mathrm{n}=28)\end{array}$ & $\begin{array}{c}\text { Group-II } \\
(\mathrm{n}=32)\end{array}$ & value \\
\hline $\mathrm{BPH}$ & $12(42.9)$ & $18(56.3)$ & 0.301 \\
Cancer & $16(57.1)$ & $14(43.7)$ & \\
\hline
\end{tabular}

\#Chi-square $\left(\chi^{2}\right)$ Test was done to analyse the data; Figures in the parentheses indicate corresponding percentage 
Complications encountered during biopsy shows that per rectal bleeding was significantly higher in the former group than that in the latter one $(p=0.015)$ (Table VIII). None of the patients developed vaso-vagal shock.

Table VII Complications during probe insertion between groups

\begin{tabular}{lccc}
\hline $\begin{array}{l}\text { Complications during probe } \\
\text { insertion }\end{array}$ & $\begin{array}{c}\text { Group-I } \\
(\mathrm{n}=28)\end{array}$ & $\begin{array}{c}\text { Group-II } \\
(\mathrm{n}=32)\end{array}$ & \\
& $0(0.0)$ & $2(6.3)$ & 0.280 \\
Vaso-vagalue & \\
Perrectal bleeding $^{\#}$ & $5(17.9)$ & $7(21.9)$ & 0.698 \\
Postpontment of procedure* $^{*}(0.0)$ & $2(6.3)$ & 0.280 \\
\hline
\end{tabular}

$\# \chi^{2}$ Test was done to analyse the data; * Data were analysed by Fisher Exact Test.

Table VIII Complications during biopsy procedure

\begin{tabular}{lccl}
\hline $\begin{array}{l}\text { Complications } \\
\text { (during biopsy) }\end{array}$ & $\begin{array}{c}\text { Group-I } \\
(\mathrm{n}=28)\end{array}$ & $\begin{array}{c}\text { Group-II } \\
(\mathrm{n}=30)\end{array}$ & \\
& $0(0.0)$ & $0(0.0)$ & - \\
\hline Vaso-vagal shock* $^{*}$ & $28(100.0)$ & $24(80.0)$ & 0.015 \\
\hline
\end{tabular}

$\# \chi^{2}$ Test was done to analyse the data; * Data were analysed by Fisher's Exact Test.

Complications encountered 30 minutes after biopsy demonstrates that haematuria, dysuria, fever and haemospermia were all equally distributed between the groups $(p>0.05)$ (Table IX).

Table IX Complications 30 minutes after biopsy

\begin{tabular}{lccc}
\hline $\begin{array}{l}\text { Complications 30 minutes } \\
\text { after biopsy }\end{array}$ & $\begin{array}{c}\text { Group } \\
\text { Group-I }\end{array}$ & $\begin{array}{c}\text { Group-II } \\
(\mathrm{n}=28)\end{array}$ & \\
& $(\mathrm{n}=30)$ & \\
\hline Macroscopic haematuria* $^{*}$ & $15(53.6)$ & $17(56.7)$ & 0.813 \\
Dysuria $^{\#}$ & $15(53.6)$ & $21(70.0)$ & 0.198 \\
Fever\# $^{\text {Perrectal bleeding }}{ }^{\#}$ & $8(28.6)$ & $10(33.3)$ & 0.695 \\
Haematospermia & $28(100.0)$ & $30(100.0)$ & - \\
\hline
\end{tabular}

* Data were analysed using Fisher Exact Test; $\# \chi^{2}$ Test was done to analyse the data.

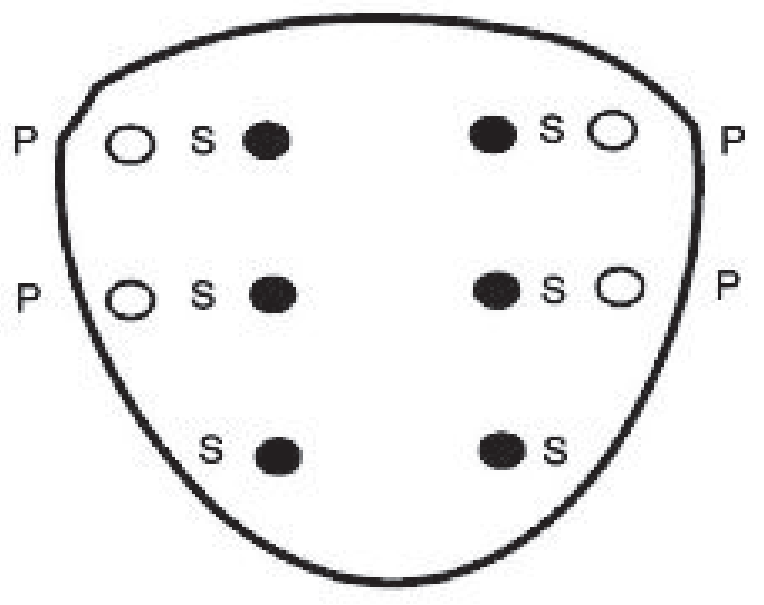

Biopsy sites of sextant (black circle) and lateral core (empty circle)

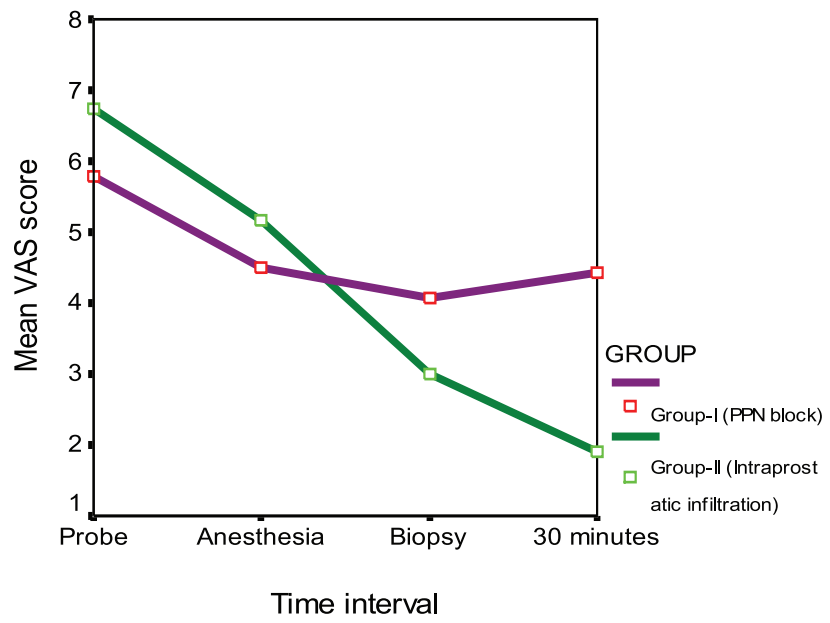

Intensity of pain at different steps of biopsy procedure

\section{Discussion}

The present study has been designed to compare the outcome of pain due prostatic biopsipy by using Intraprostatic injection and Periprostatic injection of of $2 \%$ idocaine anesthetic agent without epinephrine, nerve block duiring TRUS guided prostate biopsy. Transrectal ultrasound guided prostate biopsy is the most common method. Increasing the number of biopsies is associated with an increase in pain and morbidity, although this can improve cancer detection[6]. In addition to finite morbidity of the biopsy as far as hematuria, hemospermia, blood per rectum, and infection, the procedure can be quite uncomfortable discouraging patients from having it, especially if they need to repeat biopsy[4]. 
Most articles groups have reported the effect of PNB $[2,7,10]$. However, pain control is not satisfactory because some nerve fibers from the bundles terminate in the prostate after perforating the prostate capsule[6]. Pain experienced during biopsy might be caused by direct contact between the needle and these nerves in the stroma and prostatic capsule, which are richly innervated[5].

This may be because the nerve density is higher in the anterior zone of the prostate[3]. Recently reported that painless apical biopsy could be achieved by rotating the ultrasound probe to bypass the sensory fibers below the dentate line[6]. To minimize further pain[8], tried a completely new method, namely intraprostatic anesthesia, and compared it with traditional periprostatic anesthesia. They hypothesized that better analgesia would be achieved by anesthetizing the prostate itself, which is the source of pain. Such a method would need to block all sensory nerves, not only from the posterior, but also from the anterior side. Their results show that intraprostatic administration of local anesthesia significantly decreases pain during prostate biopsy compared with periprostatic injection.

In addition, the number of patients who had a pain score above 4 in the periprostatic group was $7(7 \%)$ and in the intraprostatic group it was $2(3 \%)$. Thus, the proportion of patients with severe pain seemed to be lower in the intraprostatic group than in the periprostatic group, although this difference was not significant $(p=0.22)$.

In this study Over three-quarter (75\%) of the subjects of Group-I and about $72 \%$ of Group-II were 65 or $>65$ years old. The mean age was almost identically distributed between the two groups $(68.1 \pm 4.7$ vs. $67.7 \pm 4.6$, $p=$ 0.734. in a study[9]. Department of Urology, Mayo Clinic, Rochester, Minnesota, was performed a prospective, double-blind techniques for preventing pain during prostate biopsy. The mean age of the patient in this study is nearly similar to the other study.

The mean pain intensity during anesthesia was also significantly less in the former group compared to the latter group ( $4.5 \pm 1.2$ vs. $5.1 \pm 1.1, p=0.036)$. Then the pain intensity of both the groups decreased, but the decrease was significantly faster and steeper in GroupII than that in Group-I $(p=0.001)$. The pain intensity of Group-II 30 minutes after biopsy further decreased to $1.9 \mathrm{~cm}$ on visual analogue scale, while the pain intensity of Group-l increased from $4.1 \mathrm{~cm}$ during biopsy to 4.4 cm 30 minutes after biopsy. $(p<0.001)$.
Histopathological diagnosis of biopsy material demonstrates that $57.1 \%$ of Group-l and $43.7 \%$ of GroupII had carcinoma prostate and the rest of the respective groups had benign hyperplasia of prostate $(\mathrm{BPH})$

In the present study, Five (17.9\%) patients of Group-I and $7(21.9 \%)$ patients of Group-II exhibited perrectal bleeding $(p=0.698)$.

In the present study, Complications encountered 30 minutes after biopsy demonstrates that haematuria, dysuria, fever and haemospermia were all equally distributed between the groups ( $p>0.05)$.

Results of the study suggest that periprostatic nerve block is not adequate and intra prostatic infiltration is better as local anesthesia during TRUS guided prostate biopsy.

\section{Summary}

The pain intensity of both the groups decreased, but the decrease was significantly faster and steeper in Group-II than that in Group-I ( $p=0.001)$. The pain intensity of Group-II 30 minutes after biopsy further decreased to $1.9 \mathrm{~cm}$ on visual analogue scale, while the pain intensity of Group-l increased from $4.1 \mathrm{~cm}$ during biopsy to $4.4 \mathrm{~cm} 30$ minutes after biopsy $(p<0.001)$. The results of the present study having no significant difference with the above mentioned studies.

Results of the study revealed that -intraprostatic administration of local anesthesia significantly decreases the pain associated with prostate biopsy compared with conventional periprostatic nerve block.

\section{Conclusion}

Intraprostatic administration of local anesthesia significantly decreases the pain associated with prostate biopsy compared with periprostatic nerve block. It is a simple, safe and rapid technique that should be considered in all patients undergoing transrectal ultrasound guided prostate biopsy. In addition, the decreased discomfort of this procedure may enable more core biopsies to be taken in patients at high risk for prostate cancer.

\section{Limitations of The Study}

i. Sample size was small.

ii. Single centre study.

iii. Stratification according to prostate volume, DRE findings, PSA level, age were not done in cancer detection. 


\section{Recommendations:}

To detect carcinoma of prostate transrectal ultrasound guided prostatic nerve blocked before biopsy diminishes the pain and discomfort associated with procedure, improving patient tolerance. Intraprostatic infiltration superior to conventional periprostatic nerve block for pain free multiple core biopsy. Urologists in our country may utilize this protocol with confidence. A large study may be done to yield more effective result.

\section{References}

1. Alavi, A. S., Soloway, M. S., Vaidya, A., Lynne, C. M. And Gheiler, E. L. 2001: 'Local anesthesia for ultrasound guided prostate biopsy: a prospective randomized trial comparing 2 methods.' J Urol, 166: 1343.

2. Berger, A. P., Frauscher, F., Halpern, E. J., Spranger, R., Steiner, H., Bartsch, G. et al 2003: 'Periprostatic administration of local anesthesia during transrectal ultrasound-guided biopsy of the prostate: a randomized double-blind placebocontrolled study.' Urology, 61: 585.

3. Collins, G. N., Lloyd, S. N., Hehir, M. and McKelvie, G. B. 1993: 'Multiple transrectal ultrasound-guided prostatic biopsies-true morbidity and patient acceptance.' Br J Urol, 71: 460.

4. Desgrandchamps, F., Meria, P., Irani, J., Desgrippes, A., Teillac, P. and Le Duc, A. 1999: 'The rectal administration of lidocaine gel and tolerance of transrectal ultrasonography-guided biopsy of the prostate: a prospective randomized placebo-controlled study.' BJU Int, 83: 1007.

5. Hollabaugh, R. S, Jr., Dmochowski, R. R. and Steiner, M. S.1997: 'Neuroanatomy of the male rhabdo sphincter.' Urology, $49 ; 426$.
6. Jones, J. S., Oder, M. and Zippe, C. D. 2002:' Saturation prostate biopsy with periprostatic block can be performed in office.' J Urol, 168: 2108.

7. Leibovici, D., Zisman, A., Siegel, Y. I., Sella, A., Kleinman, J. And Lindner, A. 2002: 'Local anesthesia for prostate biopsy by periprostatic lidocaine injection: a double-blind placebo controlled study.' J Urol, 167: 563.

8. Mutaguchi, K., Shinohara, K., Matsubara, A., Yasumoto, H., Mita, K. and Usui, T. 2005: 'Local anesthesia during 10 core biopsy of the prostate: comparison of 2 methods.' J Urol, 173: 742.

9. Obek, C., Onal, B., Ozkan, B., Onder, A. U., Yalcin, V. and Solok, V. 2002: 'Is periprostatic local anesthesia for transrectal ultrasound guided prostate biopsy associated with increased infectious or hemorrhagic complications? A prospective randomized trial.' J Urol, 168: 558.

10. Pareek, G., Armenakas, N. A. and Fracchia, J. A. 2001: 'Periprostatic nerve blockade for transrectal ultrasound guided biopsy of the prostate: a randomized double-blind, placebo controlled study.' J Urol, 166: 894.

11. Peyromaure, M., Ravery, V., Messas, A., Toublanc, M., Boccon-Gibod, L. and Boccon-Gibod, L. 2002: 'Pain and morbidity of an extensive prostate 10biopsy protocol: a prospective study in 289 patients.' J Urol, 167: 218.

12. Soloway, M. S. and Öbek, C. 2000: 'Periprostatic local anesthesia before ultrasound guided prostate biopsy.' J Urol, 163: 172. 